\title{
Model Standards OF CONDUCT FOR MEDIATORS
}

\author{
AMERICAN ARBITRATION ASSOCIATION \\ (ADOPTED SEPTEMBER 8, 2005)
}

\author{
AMERICAN BAR ASSOCIATION \\ (APPROVED BY THE ABA HOUSE OF DELEGATES AUGUST 9, 2005)

\section{ASSOCIATION FOR CONFLICT RESOLUTION (ADOPTED AUGUST 22, 2005)}

SEPTEMBER 2005

(C2005 by the American Bar Association. Reprinted with permission. All rights reserved. This information or any or portion thereof may not be copied or disseminated in any form or by any means or stored in an electronic database or retrieval system without the express written consent of the American Bar Association. 


\section{The Model Standards of Conduct for Medlators 2005}

The Model Standards of Conduct for Mediators was prepared in 1994 by the American Arbitration Association, the American Bar Association's Section of Dispute Resolution, and the Association for Conflict Resolution". A joint committee consisting of representatives from the same successor organizations revised the Model Standards in $2005^{2}$ Both the original 1994 version and the 2005 revision have been approved by each participating organization. ${ }^{3}$

\section{Preamble}

Mediation is used to resolve a broad range of conflicts within a variety of settings. These Standards are designed to serve as fundamental ethical guidelines for persons mediating in all practice contexts. They serve three primary goals to guide the conduct of mediators; to inform the mediating parties; and to promote public confidence in mediation as a process for resolving disputes.

Mediation is a process in which an impartial third party facilitates communcation and negotiation and promotes voluntary decision making by the parties to the dispute:

Mediation serves various purposes, including providing the opportunity for parties to define and clarify issues, understand different perspectives, identify interests, explore and assess possible solutions, and reach mutually satisfactory agreements, when desired.

\section{Note on Construction}

These Standards are to be read and construed in their entirety. There is no priorify significance attached to the sequence in which the Standards appear.

\footnotetext{
${ }^{1}$ The Association for Conflict Resolution is a merged erganization of the Academy of Family. Mediators, the Conflict Resolution Education Network and the Society of Professionals in Dispute Resolution (SPIDR). SPIDR was the third participating organization in the development of the 1994 Standands.

${ }^{2}$ Reporter's Notes, which are not part of these Standarts and therefore have not been specifically approved by any of the organizations, provide commentany regarding these revisions.

${ }^{3}$ The 2005 version to the Model Standards were approved by the American Bar Association's House of Delegates on August $\theta, 2005$, the Board of the Association of Conflict Resolution on August 22,2005 and the Executive Committee of the American Aibitration Association on. September 8,2005 .
} 
A NEW RELATIONSHIP BETWEEN PUBLIC AND PRIVATE

The use of the term "stiall" in a Standard indicates that the mediator must follow the practice described. The use of the term "should" indicates that the practice described in the standard is highly desirable, but not required, and is to be departed from only for very strong reasons and requires careful use of judgment and discretion.

The use of the term "mediator" is understood to be inclusive so that it applies to co-mediator models.

These Standards do not include specific temporal parameters when referencing a mediation, and therefore, do not define the exact beginning of ending of a mediation.

Various aspects of a mediation, including some matters covered by these: Standards, may also be affected by applicable law, court rules, regulations, other applicable professional rules, mediation rules to which the parties have agreed and other agreements of the parties. These sources may create conflicts with, and may take precedence over these Standards. However, a mediator should make every effort to comply with the spirit and intent of these Standards in resolving such conflicts. This effort should include honoring all remaining Standards not in conflict with these other sources.

These Standards, unless and until adopted by a court or other regulatory authority do not have the force of law. Nonetheless, the fact that these Standards have been adopted by the respective sponsoring entities, should alert mediators to the fact that the Standards might be viewed as establishing a standard of care for mediators.

\section{STANDARD I. SELF-DETERMINATION}

A. A mediator shall conduct a mediation based on the principle of party selfdetermination. Seff-determination is the act of coming to a voluntany, uncoerced decision in which each party makes free and informed choices as to process and outcome. Parties may exercise self-determination at any stage of a mediation; including mediator selection, process design, participation in or withdrawal from the process, and outcomes;

1. Although party self-determination for process design is a fundamental principle of mediation practice, a mediator may need to balance such party self-determination with a mediator's duty to conduct a quality process in accordance with these Standards.

2. A mediator cannot personally ensure that each party has made free and informed choices to reach particular decisions, but, where 
appropriate, a mediator should make the parties aware of the importance of consulting other professionals to help them make informed choices.

B. A mediator shall not undermine party self-determination by any party for reasons such as higher settlement rates, egos; increased fees or outside pressures from court personnal, program administrators, provider organizations the media or others.

\section{STANDARD II. IMPARTIAUTY}

A. A mediator shall decline a mediation if the mediator cannot conduct it in an impartial manner. Impartiality means freedom from favoritism, bias or prejudice.

B. A mediator shall conduct a mediation in an impartial manner and avoíd conduct that gives the appearance of partiality.

1. A mediator should not act with partiality or prejudice based on any participant s personal characteristics, background, values and beliefs, or perfomance at a mediation, or any other reason.

2. A mediator should neither give nor accept a gift, favor, loan or other item of value that raises a question as to the mediator's actual or perceived impartiality.

3. A mediator may accept or give de minimis gifts or incidental items or services that are provided to facilitate a mediation or respect cultural norms so long as such practices do not raise questions as to a mediator's actual or perceived impartiality:

C. If at any time a mediator is unable to conduct a mediation in an impartial manner, the mediator shall withdraw.

\section{STANDARD III. CONFLICTS OF INTEREST}

A. A mediator stall avoid a conflict of interest or the appearance of a conflict of interest during and after a mediation. A conflict of interest can arise from involvement by a mediator with the subject matter of the dispute or from any relationship between a mediator and any mediation participant, whether past or present, personal or professional, that reasonably raises a question of a mediator's impartiality. 
A NEW RELATIONSHIP BETWEEN PUBLIC AND PRIVATE

B. A mediator shall make a reasonable inquiry to determine whether there are any facts that a reasonable individual would consider likely to create a potential or actual conflict of interest for a mediator. A mediator's actions necessary to accomplish a reasonable inquiry into potential conflicts of interest may vary based on practice context.

C. A mediator shall disclose, as soon as practicable, all actual and potential conflicts of interest that are reasonably known to the mediator and could reasonably be seen as raising a question about the mediator's impartiality. After disclosure, if all parties agree, the mediator may proceed with the mediation.

D. If a mediator learns any fact after accepting a mediation that raises: a question with respect to that mediator's service creating a potential or actual conflict of interest, the mediator shall disclose it as quickly as practicable. After disclosure, if all parties agree, the mediator may proceed with the mediation.

E. If a mediator's conflict of interest might reasonably be viewed as undermining the integrity of the mediation, a mediator shall withdraw from or decline to proceed with the mediation regardless of the expressed desire or agreement of the parties to the contrary.

F. Subsequent to a mediation, a mediator shall not establish another relationship with any of the participants in any matter that would raise questions about the integrity of the mediation. When a mediator develops personal or professional relationships with parties; other individuals or organizations following a mediation in which they were involved, the mediator should consider factors such as time elapsed following the mediation, the nature of the relationships established, and services offered when determining whether the relationships might create a perceived or actual conflict of interest.

\section{STANDARD IV. COMPETENCE}

A. A mediator shall mediate only when the mediator has the necessary competence to satisfy the reasonable expectations of the parties.

1. Any person may be selected as a mediator, provided that the parties are satisfied with the mediator's competence and qualifications. Training, experience in mediation, skills, cultural understandings and other qualities are often necessary for mediator 
competence. A person who offers to serve as a mediator creates the expectation that the person is competent to mediate effectively.

2. A mediator should attend educational programs and related activities to maintain and enhance the mediator's knowledge and skills related to mediation.

3. A mediator should have available for the parties' information relevant to the mediator's training, education, experience and approach to conducting a mediation.

B. If a mediator, during the course of a mediation determines that the mediator cannot conduct the mediation competently, the mediator shall discuss that determination with the parties as soon as is practicable and take appropriate steps to address the situation, including, but not limited to, withdrawing or requesting appropriate assistance.

C. If a mediator's ability to conduct a mediation is impaired by drugs, alcohol, medication or otherwise, the mediator shall not conduct the mediation.

\section{STANDARD V. CONFIDENTIALITY}

A. A mediator shall maintain the confidentiality of all information obtained by the mediator in mediation, unless otherwise agreed to by the parties or required by applicable law.

1. If the parties to a mediation agree that the mediator may disclose information obtained during the mediation, the mediator may do so.

2. A mediator should not communicate to any non-participant information about how the parties acted in the mediation. $A$ mediator may report, if required; whether parties appeared at a scheduled mediation and whether or not the parties reached a resolution.

3. If a mediator participates in teaching, research or evaluation of mediation, the mediator should protect the anonymity of the parties and abide by their reasonable expectations regarding confidentiality.

B. A mediator who meets with any persons in private session during a mediation shall not convey directly or indirectly to any other person, any information that was obtained during that private session without the consent of the disclosing person. 


\section{A NEW RELATIONSHIP BETWEEN PUBLIC AND PRIVATE}

C. A mediator shall promote understanding among the parties of the extent to which the parties will maintain confidentiality of information they obtain in a mediation.

D. Depending on the circumstance of a mediation, the parties may have varying expectations regarding confidentiality that a mediator should address. The parties may make their own rules with respect to confidentiality, or the accepted practice of an individual mediator or institution may dictate a particular set of expectations.

\section{STANDARD VI. QUALITY OF THE PROCESS}

A. A mediator shall conduct a mediation in accordance with these Standards and in a manner that promotes diligence, timeliness, safety, presence of the appropriate participants, party participation, procedural fairness, party competency and mutual respect among all participants.

1. A mediator should agree to mediate only when the mediator is prepared to commit the attention essential to an effective mediation.

2. A mediator should only accept cases when the mediator can satisfy the reasonable expectation of the parties concerning the timing of a mediation.

3. The presence or absence of persons at a mediation depends on the agreement of the parties and the mediator. The parties and mediator may agree that others may be excluded from particular sessions or from all sessions.

4. A mediator should promote honesty and candor between and among all participants, and a mediator shall not knowingly misrepresent any material fact or circumstance in the course of a mediation.

5. The role of a mediator differs substantially from other professional roles. Mixing the role of a mediator and the role of another profession is problematic and thus, a mediator should distinguish between the roles. A mediator may provide information that the mediator is qualified by training or experience to provide, only if the mediator can do so consistent with these Standards. 
6. A mediator shall not conduct a dispute resolution procedure other than mediation but label it mediation in an effort to gain the protection of rules, statutes, or other governing authorities: pertaining to mediation.

7. A mediator may recommend, when appropriate, that parties consider resolving their dispute through arbitration, counseling, neutral evaluation or other processes.

8. A mediator shall not undertake an additional dispute resolution role in the same matter without the consent of the parties. Before providing such service, a mediator shall inform the parties of the implications of the change in process and obtain their consent to the change. A mediator who undertakes such role assumes different duties and responsibilities that may be governed by other standards.

9. If a mediation is being used to further criminal conduct, a mediator should take appropriate steps including, if necessary, postponing, withdrawing from or terminating the mediation.

10. If a party appears to have difficulty comprehending the process, issues, or settlement options, or difficulty participating in a mediation, the mediator should explore the circumstances and potential accommodations, modifications or adjustments that would make possible the party's capacity to comprehend, participate and exercise self-determination.

B. If a mediator is made aware of domestic abuse or violence among the parties, the mediator shall take appropriate steps including, if necessary, postponing, withdrawing from or terminating the mediation.

C. If a mediator believes that participant conduct, including that of the mediator, jeopardizes conducting a mediation consistent with these Standards, a mediator shall take appropriate steps including, if necessary, postponing, withdrawing from or terminating the mediation.

\section{STANDARD VII. ADVERTISING AND SOLICITATION}

A. A mediator shall be truthful and not misleading when advertising, soliciting or otherwise communicating the mediator's qualifications, experience, services and fees. 


\section{A NEW RELATIONSHIP BETWEEN PUBLIC AND PRIVATE}

1. A mediator should not include any promises as to outcome in communications, including business cards, stationery, or computerbased communications.

2. A mediator should only claim to meet the mediator qualifications of a governmental entity or private organization if that entity or organization has a recognized procedure for qualifying mediators and it grants such status to the mediator.

B. A mediator shall not solicit in a manner that gives an appearance of partiality for or against a party or otherwise undermines the integrity of the process.

C. A mediator shall not communicate to others, in promotional materials or through other forms of communication, the names of persons served without their permission.

\section{STANDARD VIII. FEES AND OTHER CHARGES}

A. A mediator shall provide each party or each party's representative true and complete information about mediation fees, expenses and any other actual or potential charges that may be incurred in connection with a. mediation.

1. If a mediator charges foes, the mediator should develop them in light of all relevant factors, including the type and complexity of the matter, the qualifications of the mediator, the time required and the rates customary for such mediation services.

2. A mediator's fee arrangement should be in writing unless the parties request otherwise.

B. A mediator shall not charge fees in a manner that impairs a mediator's impartiality.

1. A mediator should not enter into a fee agreement which is contingent upon the result of the mediation or amount of the settlement.

2. While a mediator may accept unequal fee payments from the parties, a mediator should not allow such a fee arrangement to adversely impact the mediator's ability to conduct a mediation in an impartial manner. 


\section{STANDARD IX. ADVANCEMENT OF MEDIATION PRACTICE}

A. A mediator should act in a manner that advances the practice of mediation. A mediator promotes this Standard by engaging in some or all of the following:

1. Fostering diversity within the field of mediation.

2. Striving to make mediation accessible to those who elect to use it, including providing services at a reduced rate or on a pro bono basis as appropriate.

3. Participating in research when given the opportunity, including obtaining participant feedback when appropriate.

4. Participating in outreach and education efforts to assist the public in developing an improved understanding of, and appreciation for, mediation.

5. Assisting newer mediators through training, mentoring and networking.

B. A mediator should demonstrate respect for differing points of view within the field, seek to learn from other mediators and work together with other mediators to improve the profession and better serve people in conflict. 